\title{
Study on Drop Test of Electric Vehicle Battery*
}

\author{
Guo Zhijun ${ }^{1, a}$, Li Tao ${ }^{1, b}$, Sun Zhengwei ${ }^{2 c}$, Wu Jingbo ${ }^{1, d}$ \\ ${ }^{1}$ Vehicle \& Traffic Engineering School, Henan University of Science \& Technology, Luoyang 471003 , \\ China \\ 2 Jiangling Motors Co., Ltd., Nanchang 330001, China \\ agzhij1970@163.com, bolitao2008@163.com, ${ }^{\mathrm{C}}$ zsun4@ford.com, dwubocn2005@163.com
}

Keywords: power battery; drop; test analysis; test plan

\begin{abstract}
The safety of vehicle power battery is an issue of particular concern for vehicle manufacturers, consumers and especially important for the application and development of electric vehicles. This paper introduces a drop test method of power battery, proposes a test scheme used for evaluating the drop damage. The electrical properties and safety properties of the power battery before and after drop are analyzed. It provides an effective reference for understanding the influence of drop on the electric vehicle power battery.
\end{abstract}

\section{Introduction}

As one of the important measures to alleviate the energy and environment problems, the industry of electric vehicle in China has been developed rapidly. The safety and reliability of the vehicle power batteries have been attached more and more importance. Power batteries may undergo shock or vibration from the outside world in production, transportation, usage and accident cases. After the drop test, whether the performance of power battery is affected or not, there is little research on this aspect. In this paper, a set of test scheme for the evaluation of power battery drop injury is presented. Based on this method, a lithium ion power battery pack was conducted at room temperature. The energy, capacity, internal resistance, power and cycling condition were performed in drop test before and after. By analysis and comparison, the influence of the drop on the structure and performance of the battery was explained.

\section{Test Scheme Design}

At present, there are few standards for the test of power battery pack drop at home and abroad. The new GB/T 31467.3-2015 has made the drop test method for the electric vehicle lithium ion power battery pack clear. Power battery pack or system should be dropped in the direction of the actual maintenance or installation process. If the direction is not determined, it is suggested to have the battery dropped in the $\mathrm{Z}$ axis at the height of $1 \mathrm{~m}$ and observe it for 2 hours ${ }^{[1]}$. But this method is only for drop test itself, and the results of the test only focuses on the electrolyte leakage, fire, explosions and other phenomenon of the battery pack or system.

In order to study the drop effect on the performance of lithium ion battery pack, this paper tests the energy, capacity, power, internal resistance and the driving cycle of the battery pack at room temperature before and after the drop based on the GB/T 31467.3-2015. The overcharge protection, overdischarge protection, over-temperature protection and short-circuit protection are tested after the drop. Finally, the battery pack is disassembled and X-ray inspection is carried out.

\footnotetext{
* supported by National High Technology Research and Development Program (863 Program), Project number: 2012AA111204
} 


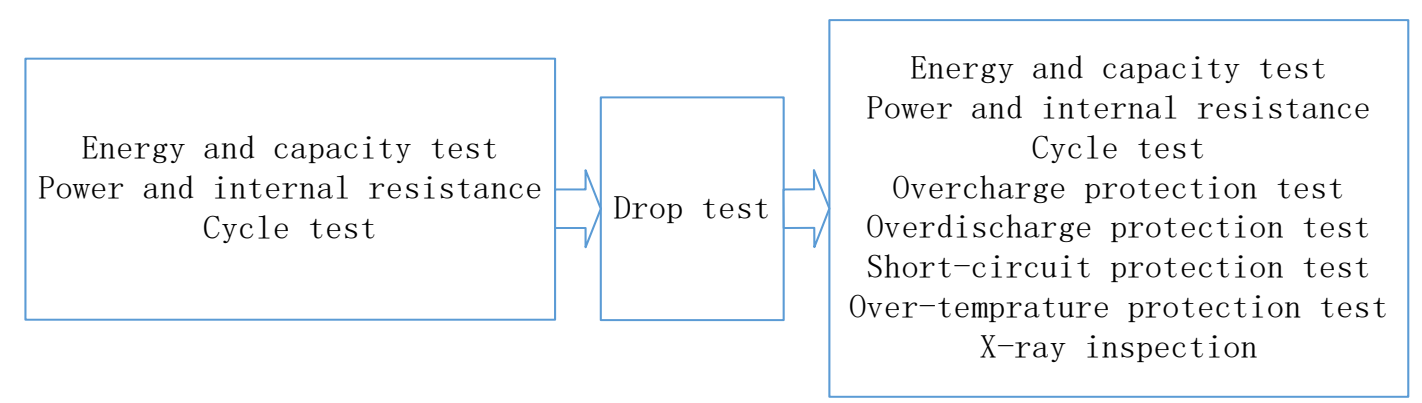

Fig. 1 Power battery drop test plan

\section{Test}

\section{Drop test.}

The test object is a lithium ion power battery pack, battery management system is integrated in the battery pack. The main external characteristic parameters are as follows: length $1730 \mathrm{~mm}$, width $1060 \mathrm{~mm}$, height $280 \mathrm{~mm}$, and mass $270 \mathrm{~kg}$.

The test battery pack is dropped from a height of $1.2 \mathrm{~m}$ onto a concrete surface ${ }^{[2]}$. The PC communicates with the battery management system through USB-CAN module, the voltage, current, temperature and alarm information of the power battery pack is under real-time monitoring in the process of falling down. When the test of the electrical properties and safety are completed, the battery pack would be dismantled and detected with X-ray.

\section{Electrical properties test.}

1) Energy and capacity test

First, place the power battery in the room for 2 hours after drop. In order to monitor the state of the battery pack in real time, the host computer should be connected with battery management system. Charge and discharge conditions are set according to the designed parameters of the battery pack. The battery is charged to $100 \%$ SOC at the rate of $\mathrm{C} / 3$, then two rounds of standard cycle are carried out. After testing the battery, leave it in static for 1 hours.

2) Power and internal resistance test

When thermal equilibration is finisded, a standard cycle is performed. The battery is dischargeed to $80 \%$ SOC at the rate of $\mathrm{C} / 3$. The power and internal resistance are tested after 30 minutes. When the SOC is $50 \%$ and $30 \%$, the battery pack is tested with the same method. Power and internal resistance test conditions are as follows ${ }^{[3]}$ (the discharging current is positive, the charging current is negative, the following is the same) 


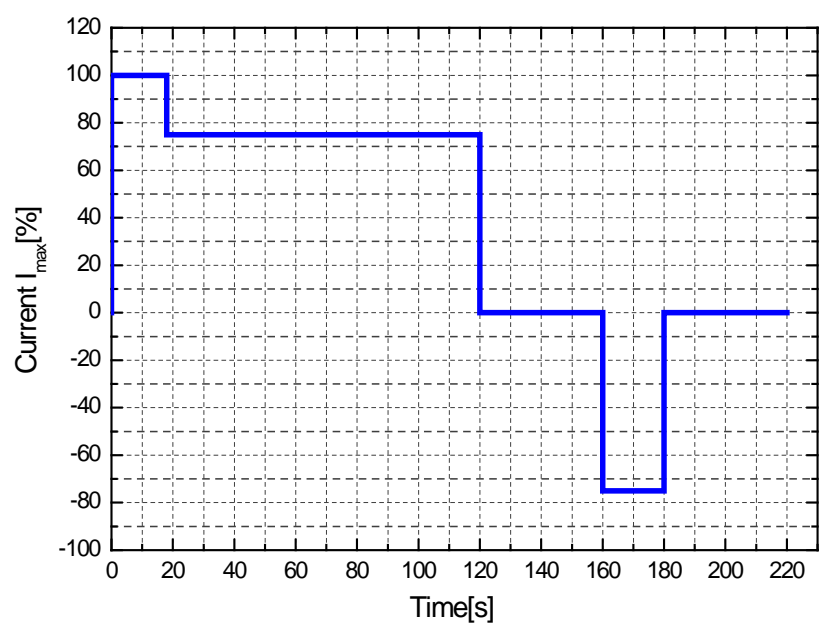

Fig 2. Pulse power characterisation profile - current

3) Cycle test

At room temperature, The power battery completed a charge and discharge cycle at the rate of C/3 after thermal equilibration, then put the battery in static for $30 \mathrm{~min}$ to perform a standard cycle. Perform the dynamic discharge power curve I in the full power state, then the dynamic discharge power curve II. The two kinds of dynamic discharge power curves operated alternatively until the SOC is $20 \%{ }^{[4,5]}$.

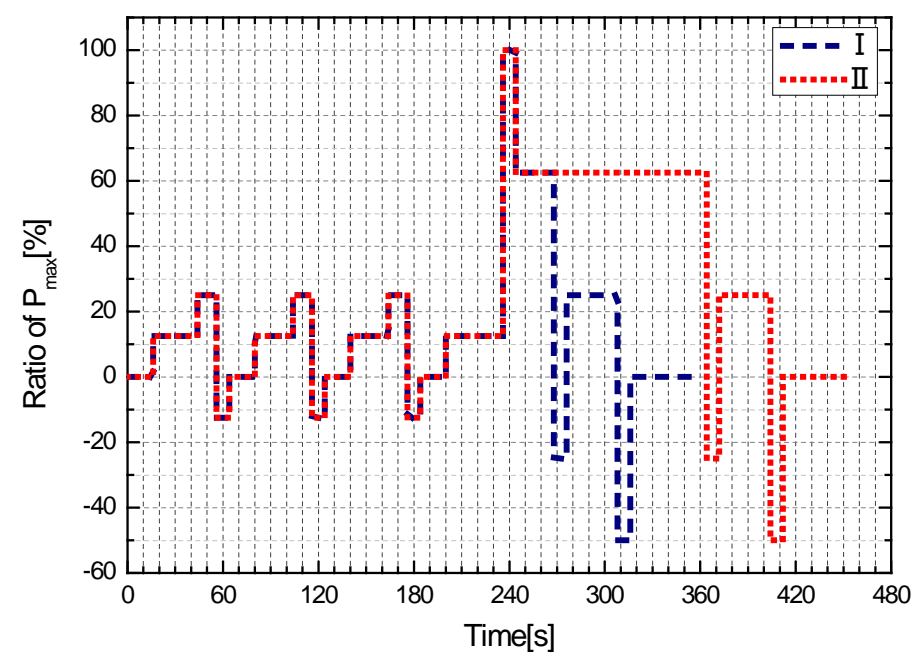

Fig 3. Dynamic discharge power profiles

\section{Safety tests.}

1) Overcharge protection test

The host computer sends command to the battery management system to close contactors. Then the battery pack is charged with a charge rate of $1 \mathrm{C}$ until the BMS works. The test is set to cut off when the voltage of the battery pack reaches 1.2 times of its maximum allowable value or when the SOC reaches a level of $130 \%{ }^{[6]}$.

2) Overdischarge protection test

Discharge the battery with a charge rate of $1 \mathrm{C}$ to the discharge cut off condition. And then continue discharging with the same rate until the BMS works. The test is set to cut off when the voltage of the battery pack descends less than $25 \%$ of the rated voltage or the discharging time is more than 30 min. After the experiment, observe for 2 hours. 
3) Over-temperature protection test

In order to accelerate the test, put the battery pack into a Walk-in environment warehouse. Heat the Environmental chamber at the rate of $2^{\circ} \mathrm{C} / \mathrm{min}$, and discharge the battery with a charge rate of $1 \mathrm{C}$ at the same time until the BMS works. The test is set to cut off when the battery pack temperature exceeds $10^{\circ} \mathrm{C}$ than its maximum allowable value or the maximum temperature change less than $4^{\circ} \mathrm{C}$ in one hour.

4) Short-circuit protection test

With the power battery of full SOC, external short circuit test is performaced by the short circuit testing machine. The short circuit resistance value is $10 \mathrm{~m} \Omega$. The test is set to cut off when the Short circuit time is more than $10 \mathrm{~min}$ or the fuse blows out.

\section{Results and discussion}

\section{Battery pack drop test.}

After the drop, there is no phenomenon of electrolyte- leakage, smoking, fire or explosion etc. with the battery. Measured with AC insulation resistance tester, the positive insulation resistance value is $4247 \Omega / \mathrm{V}$, and the negative electrode insulation resistance value is $6575 \Omega / \mathrm{V}$. It appears some obvious gaps in some seal adhesive joints of the upper and the lower body, and there is a clear crack at the rear bending place. The waterproof test proved that the sealing of the battery pack had been destroyed ${ }^{[7]}$. After dismantling, we find that there is no obvious deformation and fracture of the internal structure of the battery pack and no obvious displacement of the monomers and the modules. According to the $\mathrm{X}$-ray inspection, there are some cracks and voids in some areas of the lower body of cast aluminum. As a result, the external structure of the battery pack still needs to be improved, such as enhancing the mechanical strength of the rear part of the battery pack, improving the production process and the sealing of the battery pack.

\section{Comparison of battery electrical properties before and after drop.}

1) Energy and capacity

As shown in Figure 4, the voltage platform does not change after the drop while charging. The charge curve remains almost the same from the beginning of the charge to the end. The Charge energy and capacity reduction are both less than $1 \%$. But the ending voltage of the battery is slightly higher than that before the drop. There is a significant difference in the first half of the discharge curve, and the voltage of the platform has changed greatly while discharging. Discharge capacity decreases from 67.67Ah to $68.3 \mathrm{Ah}$, discharge energy decreases from $21.79 \mathrm{kWh}$ to $21.1 \mathrm{kWh}$, thus capacity and energy are attenuated by $0.92 \%$ and $3.17 \%$ respectively.

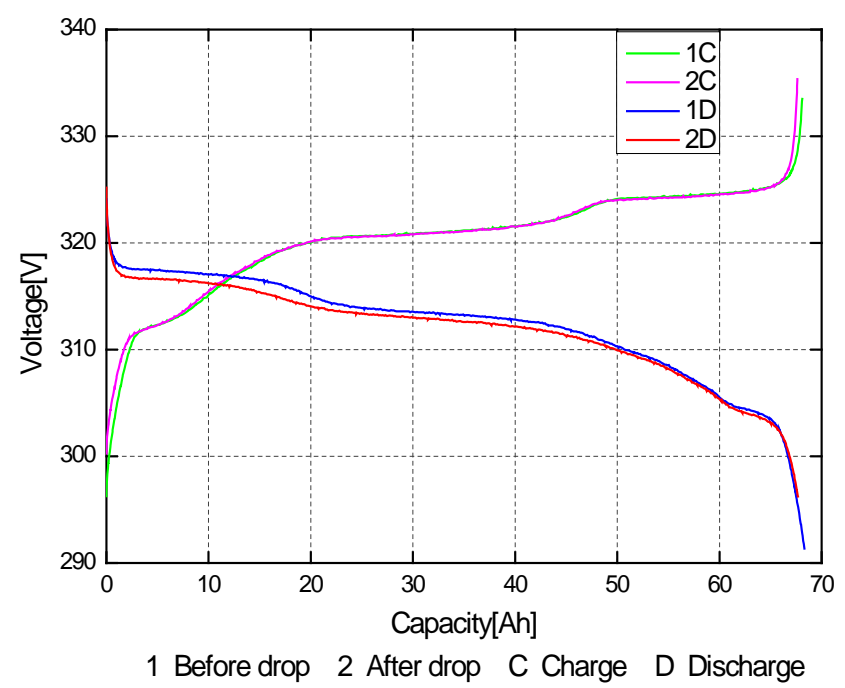

Fig. 4 Battery charge and discharge curves before and after drop

2) power and resistance 
Through the charge and discharge test, the discharge power and discharge resistance in 3 different SOC conditions are calculated and shown in table 1 . According to the table, the internal resistance has increased after the drop. At SOC of $80 \%$, of $50 \%$ and of $30 \%$, the internal resistance increased by $3.57 \%, 3.2 \%$ and $2.55 \%$ respectively. There is no obvious decrease of the discharge power, and there is no difference between the discharge power in the half power state before and after drop.

Table 1 Battery power and internal resistance before drop

\begin{tabular}{cccc}
\hline SOC & $80 \%$ & $50 \%$ & $30 \%$ \\
\hline Charging power[kW] & 53.3 & 52.9 & 52.5 \\
Discharging power[kW] & 49.3 & 48.8 & 48.3 \\
Charging internal resistance $[\mathrm{m} \Omega]$ & 67.7 & 68.6 & 68.4 \\
Discharging internal resistance $[\mathrm{m} \Omega]$ & 75.7 & 78.1 & 78.3 \\
\hline
\end{tabular}

Table 2 Battery power and internal resistance after drop

\begin{tabular}{cccc}
\hline SOC & $80 \%$ & $50 \%$ & $30 \%$ \\
\hline Charging power[kW] & 53.3 & 52.9 & 52.5 \\
Discharging power[kW] & 49.2 & 48.8 & 48.2 \\
Charging internal resistance $[\mathrm{m} \Omega]$ & 69.4 & 69.9 & 69.7 \\
Discharging internal resistance $[\mathrm{m} \Omega]$ & 78.4 & 80.6 & 80.3 \\
\hline
\end{tabular}

3) Cycle Test

After the test of 6 cycles, the discharge energy of the battery was decreased only by $0.1 \mathrm{kWh}$. It is seen that the drop of the battery had no obvious effect on the normal charge and discharge of the battery in such condition. Battery pack temperature rise has also declined than it before the drop, which is largely due to the battery pack sealing performance gets worse and the heat dissipation of the battery pack has been improved to some extent.

Table 3 Discharge energy and temperature rise before and after drop

\begin{tabular}{ccccc}
\hline & $\begin{array}{c}\text { Discharge } \\
\text { energy[kWh] }\end{array}$ & $\begin{array}{c}\text { Maximum } \\
\text { temperature } \\
\text { rise }\left[{ }^{\circ} \mathrm{C}\right]\end{array}$ & $\begin{array}{c}\text { Minimum } \\
\text { temperature } \\
\text { rise }\left[{ }^{\circ} \mathrm{C}\right]\end{array}$ & $\begin{array}{c}\text { Average } \\
\text { temperature } \\
\text { rise }\left[{ }^{\circ} \mathrm{C}\right]\end{array}$ \\
\hline Before drop & 18.8 & 15 & 9 & 12 \\
After drop & 18.9 & 13 & 8 & 11 \\
\hline
\end{tabular}

\section{The safety of battery pack after drop.}

The battery management system can timely cut off the relay in the test of abuse protection. Power battery pack will not undergo shell rupture, smoke, fire, or explosion, etc. and the insulation resistance is $4000 \Omega / \mathrm{V}$ above. The relay is disconnected when the maximum voltage of the single battery is greater than $3.8 \mathrm{~V}$ about $1.1 \mathrm{~s}$ in the test of overcharge protection. In addition the lowest voltage of the single battery is less than $2.3 \mathrm{~V}$ about $0.7 \mathrm{~s}$.

The battery management system had cut off the relay when the highest temperature of the battery pack over $65^{\circ} \mathrm{C}$ in $200 \mathrm{~ms}$. The battery pack had no air, fire, or explosion, and the insulation resistance value meets the requirement. The full power state of the battery pack for a short circuit, the fuse fused in $15 \mathrm{~ms}$, the battery pack was been protected well. At the same time, the high voltage relay could also be in a good working condition, and the battery did not appear in other abnormal situation. 


\section{Conclusions}

In this paper, the lithium ion power battery pack had been used for the drop test. According to the proposed test plan, energy and capacity, power and resistance and cycle test were carried our before and after drop. In addition, the abuse protection test was also performed after drop. The safety of the battery pack meets existing standards without electrolyte leakage, fire or explosion phenomenon. $\mathrm{X}$-ray inspection found battery pack had cracks or voids. The comparative tests show that the battery pack dropped has larger resistance, less energy and capacity. But discharge power had no significant different compared with that of before. The battery management system still plays a protective role, and the fuse can also be normal.

\section{References}

[1] GB/T 31467.3-2015 Lithium-ion traction battery pack and system for electric vehicles-Part 3: Safety requirements and test methods[S].2015.

[2] IEC 60086-4 Primary batteries-Part 4: Safety of lithium batteries[S].2007.

[3] ISO 12405-2-2012 Electrically propelled road vehicles -- Test specification for lithium-ion traction battery packs and systems -- Part 2: High-energy applications[S].2012.

[4] DOE/ID-10479, USABC Electric Vehicle Battery Test Procedure Manual[S].1996.

[5] Moss P L, Au G, Plichta E J, et al. Study of capacity fade of lithium-ion polymer rechargeable batteries with continuous cycling[J]. J Electrochem Soc, 2010, 157(1):A1-A7.

[6] Sand 2005-3123. Electrical Energy Storage System Abuse Test Manual for Electric Hybrid Electric Vehicle Application[S]. USA: FreedomCAR, 2005.

[7] GB 4208-2008 Degrees of protection provided by enclosure(IP code)[S].2008. 